\title{
Pick-up, transport and release of a molecular cargo using a small-molecule robotic arm
}

DOI:

10.1038/nchem.2410

\section{Document Version}

Accepted author manuscript

Link to publication record in Manchester Research Explorer

\section{Citation for published version (APA):}

Kassem, S., Lee, A. T. L., Leigh, D., Augustinas Markevicius, \& Jordi Solà (2015). Pick-up, transport and release of a molecular cargo using a small-molecule robotic arm. Nature Chemistry, 8, 138-143.

https://doi.org/10.1038/nchem.2410

\section{Published in:}

Nature Chemistry

\section{Citing this paper}

Please note that where the full-text provided on Manchester Research Explorer is the Author Accepted Manuscript or Proof version this may differ from the final Published version. If citing, it is advised that you check and use the publisher's definitive version.

\section{General rights}

Copyright and moral rights for the publications made accessible in the Research Explorer are retained by the authors and/or other copyright owners and it is a condition of accessing publications that users recognise and abide by the legal requirements associated with these rights.

\section{Takedown policy}

If you believe that this document breaches copyright please refer to the University of Manchester's Takedown Procedures [http://man.ac.uk/04Y6Bo] or contact uml.scholarlycommunications@manchester.ac.uk providing relevant details, so we can investigate your claim.

\section{OPEN ACCESS}




\title{
Pick-up, Transport and Release of a Molecular Cargo using a Small-Molecule Robotic Arm
}

\author{
Salma Kassem, Alan T. L. Lee, David A. Leigh, ${ }^{*}$ Augustinas Markevicius, Jordi Solà \\ School of Chemistry, University of Manchester, Oxford Road, Manchester M13 9PL, United \\ Kingdom
}

\begin{abstract}
Modern day factory assembly lines often feature robots that pick up, reposition and connect components in a programmed manner. The idea of manipulating molecular fragments in a similar way has to date only been explored using biological building blocks (DNA). Here we report on a wholly artificial small-molecule robotic arm capable of selectively transporting a molecular cargo in either direction between two spatially distinct, chemically similar, sites on a molecular platform. The arm picks up/releases a 3mercaptopropanehydrazide cargo by formation/breakage of a disulfide bond, while dynamic hydrazone chemistry controls the cargo binding to the platform. Transport is controlled by selectively inducing conformational and configurational changes within an embedded hydrazone rotary switch that steers the robotic arm. In a three-stage operation $79-85 \%$ of 3 mercaptopropanehydrazide molecules are transported in either (chosen) direction between the two platform sites, without the cargo at any time fully dissociating from the machine nor exchanging with other molecules in the bulk.
\end{abstract}

The mechanical manipulation of matter at atomic length-scales has fascinated scientists since it was proposed by Feynman in 'There's Plenty of Room at the Bottom'.' Drexler has suggested that nanoscale machines should be capable of mechanically positioning atoms, or clusters of atoms, with sufficient precision that they could one day be used to assemble almost any substance or material. ${ }^{2,3}$ However, although individual molecules and atoms can be manipulated with exquisite spatial accuracy using scanning tunnelling and atomic force microscopies, ${ }^{4}$ Smalley ${ }^{5}$ and others ${ }^{6,7}$ have argued that molecular-sized 'Drexlerian assemblers' cannot be realized, at least not that operate in the way envisaged, as each successive step down towards the nanoscale would increasingly magnify constraints on the assembler (the socalled 'sticky fingers' and 'fat fingers' problems ${ }^{5-7}$ ). 
Nevertheless, the idea of using molecules to manipulate other molecules in robotic fashion is an intriguing one that has some precedence in biology: for example, in metazoan fatty acid synthase a growing fatty acid chain, tethered to an embedded carrier protein, is passed between enzyme domains in the protein superstructure in a manner reminiscent of the way a robotic arm manipulates objects on a factory assembly line. ${ }^{8-10}$ DNA has been used to make mechanical systems ${ }^{11}$ and dynamic structures that can transport gold nanoparticles, ${ }^{12}$ but DNA machines are typically 100-1000x larger in mass/volume than comparable small-molecule systems and, whilst DNA has advantages in terms of ease of structural programing and synthesis, it is limited as a construction material in terms of operating conditions and chemical stability compared to wholly synthetic structures. ${ }^{13}$ Small-molecule machines have been developed that can perform mechanical tasks at the macroscopic level ${ }^{14-18}$ and a photoresponsive host molecule has been described that is able to mechanically twist a bound molecular guest. ${ }^{19}$ Here we report on a molecular machine that is able to pick up a cargo, reposition it, set it down and release it at a second site approximately $2 \mathrm{~nm}$ away from the starting position. The relocation of molecular fragments with a molecular robotic armmaking and breaking covalent bonds in a process during which the substrate is unable to exchange with others in the bulk-is a step towards the controlled manipulation of molecularlevel structures through programmable small-molecule robotics. In chemical terms it is the selective synthesis of constitutional isomers through intramolecular rearrangements that can be induced to proceed in either direction, something that is difficult or impossible to achieve in other ways.

\section{Results and Discussion}

\section{Design}

The design of a bidirectional small-molecule transporter system, $\mathbf{1}$, is shown in Fig. 1. It features two sites (blue and green) for a cargo (red) at either end of a rigid molecular platform to which is attached a 'robotic' arm (i.e. an appendage that can grip, manoeuvre and release an object, and its position with respect to the platform is both well-defined and subject to change in response to a specific stimulus). The arm is steered by a rotary switch (orange) embedded in the middle of the platform, with redox reactions mediating covalent bond formation between the cargo and the arm. Machines need to be designed according to the environment they will function in $^{20,21}$ and the difference in the way matter behaves at different length scales means 
that a machine intended to mechanically transport a cargo between sites $2 \mathrm{~nm}$ apart cannot operate through the same mechanism as one that does so over $2 \mathrm{~m} \cdot{ }^{7,20,21}$ Gravity is irrelevant at the molecular level and to stop the cargo exchanging with other cargo molecules in the bulk, or those associated with other platforms or robotic arms, the same cargo molecule must be bound to the machine ensemble at the start, throughout transport, and at the end. Dynamic covalent chemistry allows for such a process: ${ }^{22-24}$ the cargo-platform linkage was chosen to be a hydrazone group able to exchange between aldehydes (the platform sites) under acid conditions but kinetically inert under basic conditions; the cargo-arm linkage was selected as a disulfide bond that is dynamic under basic conditions but locked under acidic conditions. Accordingly, at no time during the operation of the molecular machine can the cargo detach fully from both the platform and the robotic arm.

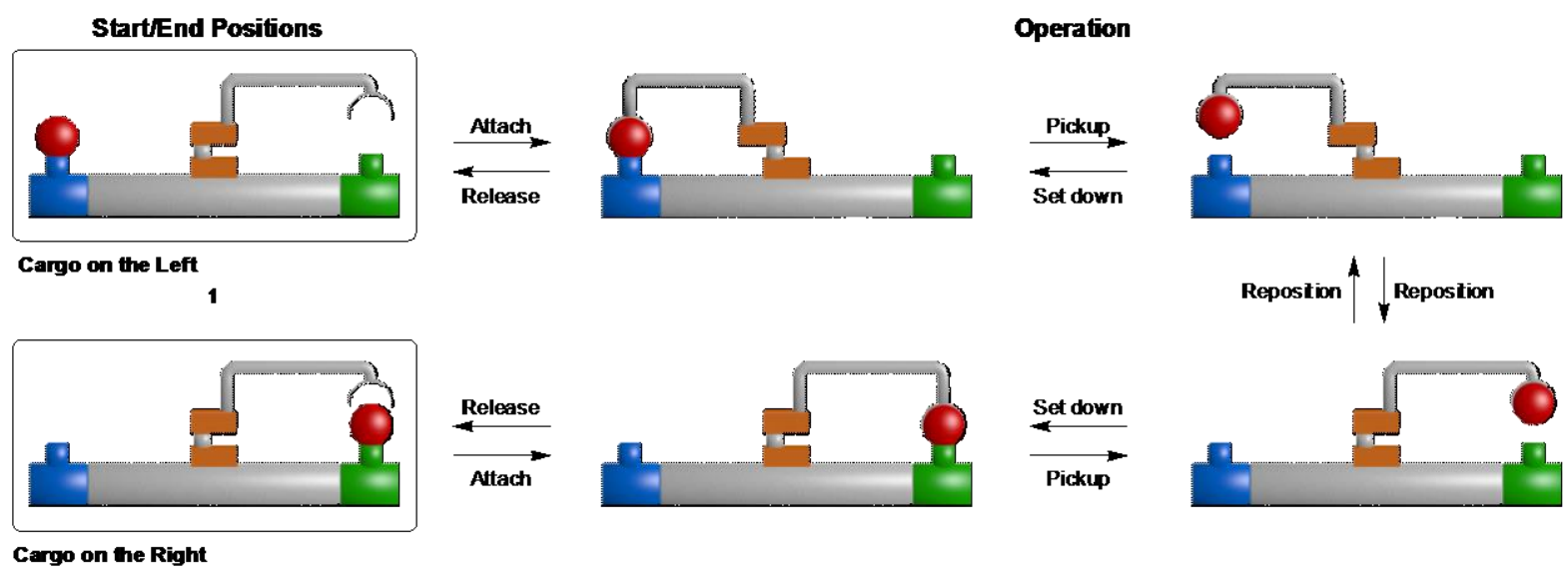

Figure 1. Multi-stage operation of a bidirectional small-molecule transporter system, 1, that uses a rotary switch to control a molecular robotic arm. Stage one (attach): toggling the switch (orange) from its initial state, if necessary, steers the arm to be proximate to the cargo (red ball) enabling it to attach to the substrate by reversible covalent bond formation; stage two (pickup, reposition, set down): conditions are changed so that the cargo can no longer detach from the arm and the switch mechanism causes bond rotation resulting in transport of the substrate between the two platform sites (blue and green; the cargo-platform linkages need to be dynamic under these conditions); Stage three (release): cleavage of the cargo-arm bond releases the substrate at the new site and the switch (and robotic arm) can be reset to the original position(s).

The steering mechanism for the robotic arm must hold the rotor (the robotic arm) and stator (the platform) in fixed relative orientations in both states of the switch for the arm to be able to select and deliver the substrate to the correct site with high fidelity. This structural requirement is rare amongst the molecular switches developed to date. ${ }^{25}$ However, a hydrazone-based rotary switch developed by Aprahamian, ${ }^{26-28}$ containing a quinoline stator and a pyridine group as part of the rotor, was identified as suitable for this purpose. Selective protonation of various groups within the switch induces configurational and conformational 
changes involving bond rotations about two different axes (featuring tautomerisation of the conjugated system and rotation about the $\mathrm{C}_{\text {ary }} \mathrm{l}-\mathrm{N}$ bond, the latter driven by the protonation state of the quinolone group), resulting in different relative positions and orientations of the rotor and stator about the hydrazone bond (see Supplementary Fig. 15). By incorporating the quinoline unit into a rigid platform and using the rotor to control the directional movement of a mechanical arm, we envisaged that a bidirectional transporter system could be achieved (Figs 2-4). Controlled protonation of the rotary switch to favour a particular conformational/configurational isomer should be able to selectively direct the arm towards either the green or blue (deuterated) site as desired. The platform has o-methylphenyl groups between the quinoline unit and the benzaldehyde groups to provide rigidity (folding would compromise the ability of the arm to select between the platform sites), while the enforced out-of-plane conformation of adjacent aromatic rings in the platform reduces conjugation and planarity of the molecule, factors that might otherwise adversely affect chemical stability and solubility. The robotic arm has a rigid element ( $m$-substituted phenyl ring) where it is attached to the switch and a more flexible propyl chain next to the 'cargo-gripping' thiol group. The former reduces the likelihood of the arm overreaching to pick up/release the cargo from the 'wrong' platform site; the latter affords degrees of freedom so that attaching of the arm to the cargo (which will already be bound to the platform, forming a macrocycle) does not produce a strained conformation. The cargo, which needs to possess both thiol and hydrazide groups to bind to the robotic arm and platform sites, respectively, was chosen to be 3mercaptopropanehydrazide (red, Figs 2 and 4 ).

\section{Synthesis and characterization}

Transporter-cargo conjugate EZ-1-left (cargo on the blue platform site) was prepared according to Fig. 2 (see Supplementary Information for experimental procedures and compound characterization). [Note: The italicized prefix of the compound number refers to the configuration of the imine bond of the hydrazone rotary switch ( $E Z$ means a mixture of $E$ and $Z$ ). The suffix indicates the location of the 3-mercaptopropanehydrazide cargo (-left on the deuterated (blue) platform site; -right on the non-deuterated (green) platform site). The bold number denotes the oxidation level of the machine-cargo ensemble, i.e. whether the arm is attached to the cargo (1 two thiol groups; 2 macrocyclic disulfide).] 
The key synthetic step (Fig. 2, step a) was a modified Japp-Klingemann ${ }^{29}$ reaction to form the hydrazone unit of the rotary switch, which proceeded in $81 \%$ yield (intramolecular hydrogen bonding favours the $E$-isomer ${ }^{26}$ ). The 3-mercaptopropanehydrazide cargo was loaded onto the arm by irreversible disulfide transfer, following which macrocyclization through hydrazone exchange promoted by three equivalents of trifluoroacetic acid afforded Z-2-left in $57 \%$ yield (Fig. 2, steps b and c). Subsequent reduction with tris(2-carboxyethyl)phosphine (TCEP) gave EZ-1-left (a 7:3 ratio of E-1-left:Z-1-left; Fig. 2, step d). A similar sequence of transformations, switching the configuration of the rotary switch in the opposite sense, afforded transportercargo conjugates E-2-right and EZ-1-right, with the cargo on the green platform site (see Supplementary Information).

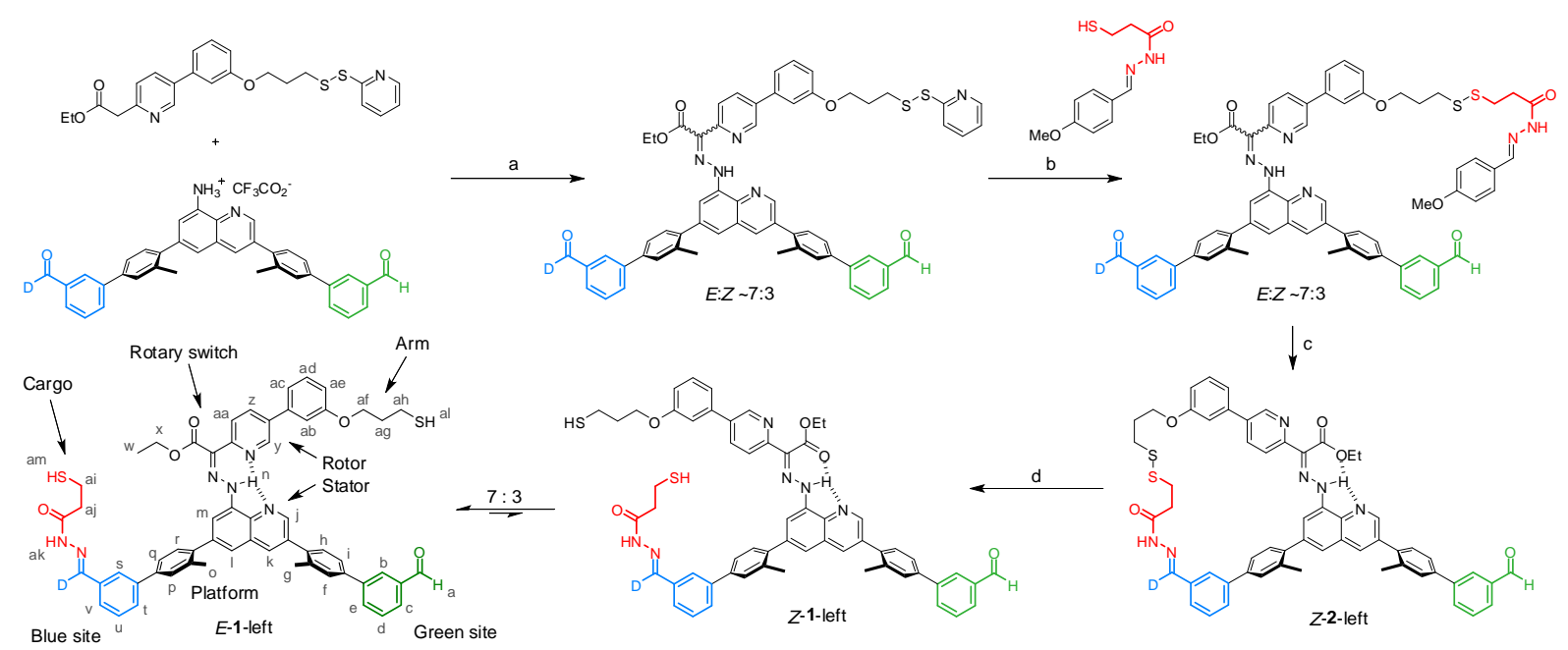

Figure 2. Synthesis of transporter-cargo conjugates Z-2-left and EZ-1-left. Reagents and conditions: a) i. $\mathrm{CF}_{3} \mathrm{CO}_{2} \mathrm{H}, t$-BuONO$, \mathrm{CH}_{2} \mathrm{Cl}_{2},-10{ }^{\circ} \mathrm{C}, 2 \mathrm{~h}$; ii. $\mathrm{KOAc}, \mathrm{CH}_{2} \mathrm{Cl}_{2},-10{ }^{\circ} \mathrm{C}$ to r. t., $2 \mathrm{~h}, 81$ $\%, E: Z \sim 7: 3$; b) $\mathrm{AcOH}, \mathrm{CH}_{2} \mathrm{Cl}_{2}, 16 \mathrm{~h}, 80 \%$; c) $\mathrm{CF}_{3} \mathrm{CO}_{2} \mathrm{H}$ (3 equiv.), $\mathrm{CHCl}_{3}(2.5 \mathrm{mM}), 48 \mathrm{~h}, 57 \%$; d) TCEP.HCl, $\mathrm{Et}_{3} \mathrm{~N}, \mathrm{C}_{2} \mathrm{H}_{2} \mathrm{Cl}_{4} / \mathrm{DMSO}(2: 1)$, r. t., 16 h, $80 \%$. TCEP = tris(2-carboxyethyl)phosphine.

The ${ }^{1} \mathrm{H}$ NMR chemical shifts of several protons of the machine-cargo ensemble are diagnostic of the location and oxidation state of the cargo and the configuration of the hydrazone switch, enabling them to be followed throughout the operation of the molecular machine. The ${ }^{1} \mathrm{H}$ NMR spectra (6oo MHz, $295 \mathrm{~K}, \mathrm{CD}_{2} \mathrm{Cl}_{2}$ ) of the transporter-cargo conjugates EZ-1-left, Z-2-left, E-2-right and EZ-1-right are shown in Fig. 3. The similarity between the spectra of positional isomers EZ-1-left (Fig. 3a) and EZ-1-right (Fig. 3d), where the molecules differ only in whether the cargo is on the blue or green site, is immediately apparent. More subtle differences are observed between the analogous macrocycles Z-2-left and E-2-right, reflecting their different conformations, configurations and hydrogen bonding networks (Figs $3 \mathrm{~b}$ and $3 \mathrm{c}$ ). Z-2-left is a $\sim 85: 15$ mixture of acyl hydrazone bond rotamers (i.e. rotation about the platform-substrate 
$\mathrm{HN}-\mathrm{CO}$ bond) whereas E-2-right is present as a single rotamer, reflecting the difference in strain between the two macrocycles. The deuterium labelling of one of the aldehyde/imine platform sites (shown in blue) provides a probe for the location of the cargo molecule: When the cargo resides on the blue site (EZ-1-left and Z-2-left) $\mathrm{H}_{\mathrm{a}}$ (shown in green in Fig. 3) appears as an aldehyde signal at $10.12 \mathrm{ppm}$; when the cargo is placed on the green site (EZ-1-right and E-2-right) proton $\mathrm{H}_{\mathrm{a}}$ correlates to an imine signal at 7.82-7.85 $\mathrm{ppm}$.

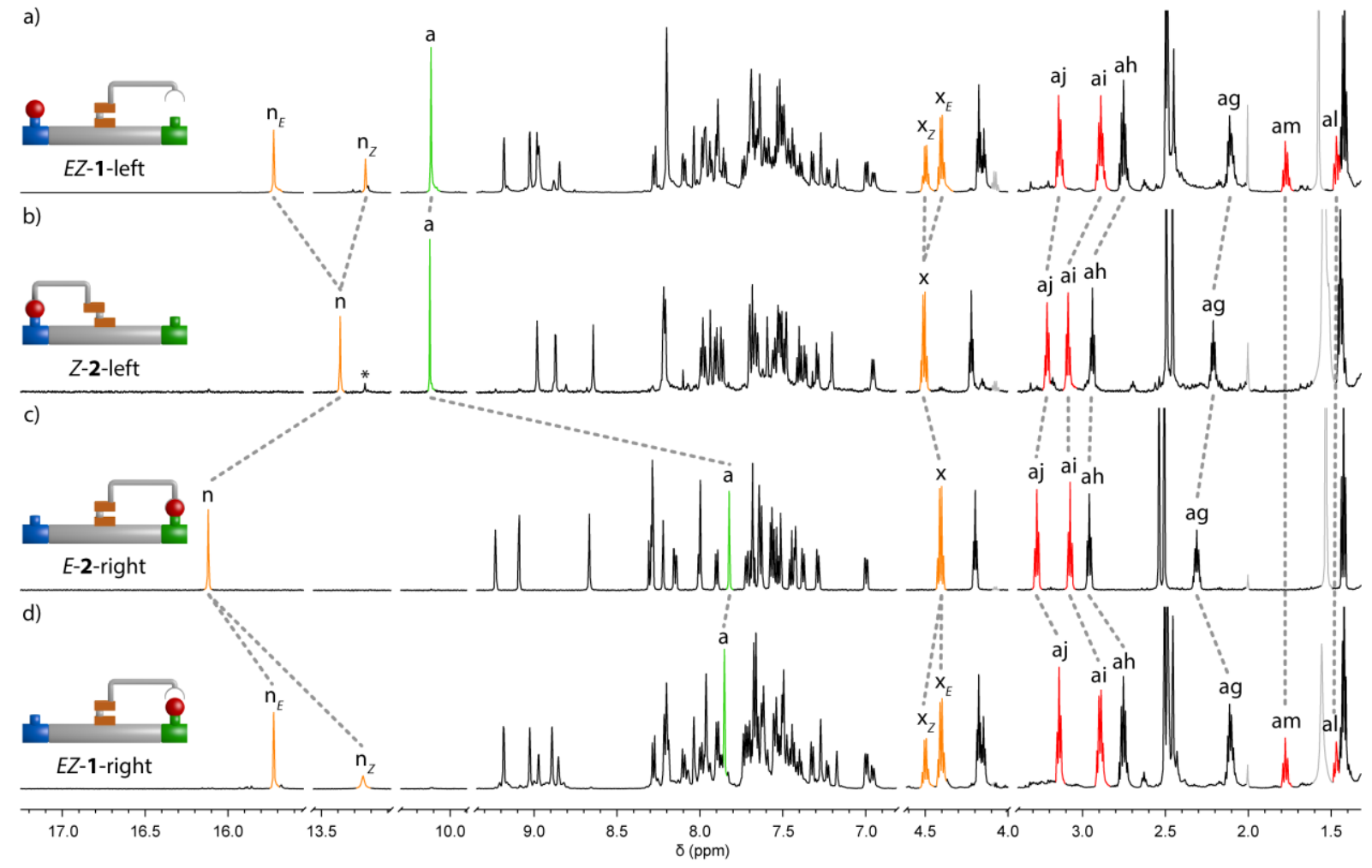

Figure 3. Partial ${ }^{1} \mathrm{H}$ NMR $\left(600 \mathrm{MHz}, 295 \mathrm{~K}, \mathrm{CD}_{2} \mathrm{Cl}_{2}\right)$ spectra of the transporter-cargo conjugates at distinctive stages of operation. (a) EZ-1-left, (b) Z-2-left, (c) E-2-right and (d) EZ-1right. Each compound was prepared by an unambiguous synthetic route, see Supplementary Information. Dashed lines connect resonances indicative of the configuration of the hydrazone switch $\left(\mathrm{H}_{\mathrm{n}}\right.$ and $\left.\mathrm{H}_{\mathrm{x}}\right)$, position of the cargo $\left(\mathrm{H}_{\mathrm{a}}\right)$ and redox state of the thiol/disulfide groups $\left(\mathrm{H}_{\mathrm{al}}\right.$ and $\left.\mathrm{H}_{\mathrm{am}}\right)$. Proton assignments correspond to the lettering in Fig. 2. Signals from traces of residual solvent are shown in gray. Some small signals, e.g. *, are due the minor acyl hydrazone rotamer (restricted rotation about the $\mathrm{NH}-\mathrm{CO}$ bond) of the cargo.

When the robotic arm is not bound to the cargo (EZ-1-left and EZ-1-right), the transporter exists as a $\sim 7: 3 E: Z$ equilibrium mixture (Figs za and 3 d), with the arm predominantly to the side of the green platform site. Chemical shifts of protons $H_{n}$ and $H_{x}$ are characteristic of the configuration of the hydrazone switch (each non-macrocyclic configurational isomer exists as a 85:15 mixture of acyl hydrazone rotamers). For positional isomers E-1-left (Fig. 3a) and E-1right (Fig. 3d) the signal of $\mathrm{H}_{\mathrm{n}}$ appears at $\sim 15.7 \mathrm{ppm}$ and $\mathrm{H}_{\mathrm{x}}$ at $4.4 \mathrm{ppm}$ as a result of hydrogen 
bonding of $\mathrm{H}_{\mathrm{n}}$ to the pyridine and quinoline nitrogen atoms (as shown for E-1-left in Fig. 2). In the corresponding minor configurational isomers, Z-1-left and Z-1-right, $\mathrm{H}_{n}$ is hydrogen bonded to the quinoline nitrogen and the carbonyl group of the ester (as shown for Z-1-left in Fig. 2), shifting these proton resonances to $\sim 13.2 \mathrm{ppm}\left(\mathrm{H}_{\mathrm{n}}\right)$ and $4.5 \mathrm{ppm}\left(\mathrm{H}_{\mathrm{x}}\right)$. Macrocycles Z-2left and E-2-right have distinctive downfield shifts of proton $\mathrm{H}_{\mathrm{n}}(13.38 \mathrm{ppm}$ and $16.12 \mathrm{ppm}$, respectively; Figs $3 \mathrm{~b}$ and $3 \mathrm{c}$ ) compared to the non-macrocyclic reduced forms, indicative of stronger hydrogen bonding within these structures. The reduced thiols in EZ-1-left and EZ-1right feature protons $\mathrm{H}_{\mathrm{am}}(1.77 \mathrm{ppm})$ and $\mathrm{H}_{\mathrm{al}}(1.46 \mathrm{ppm})$, not present in the macrocyclic disulfides, and upfield shifts of the methylene signals of the cargo $\left(\mathrm{H}_{\mathrm{ai}}\right.$ and $\left.\mathrm{H}_{\mathrm{aj}}\right)$ and the robotic $\operatorname{arm}\left(\mathrm{H}_{\mathrm{ag}}\right.$ and $\left.\mathrm{H}_{\mathrm{ah}}\right)$.

\section{Operation}

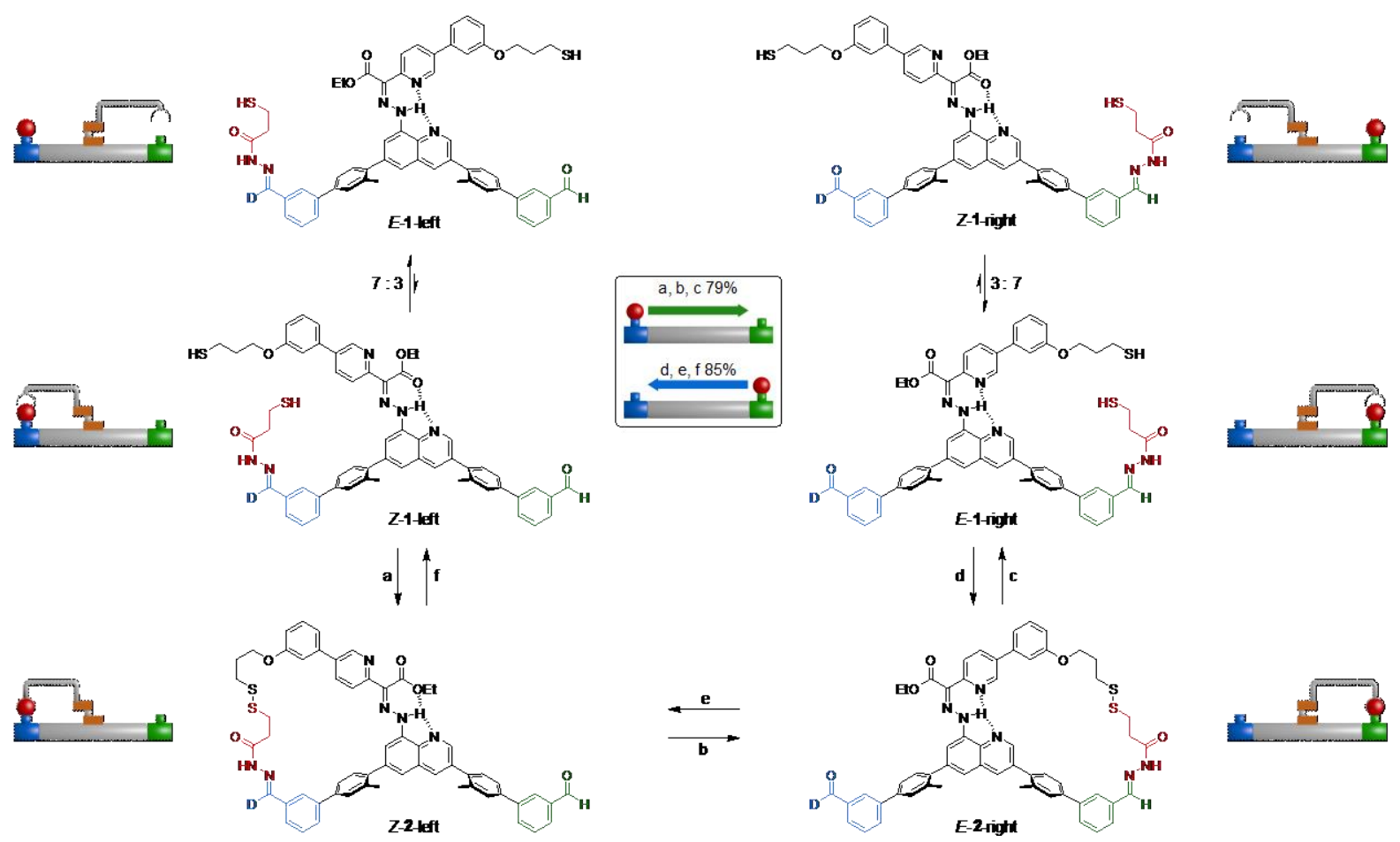

Figure 4. Operation of the molecular transporter to reposition a 3-mercaptopropanehydrazide cargo from blue-to-green or green-to-blue platform sites. The structures shown are those present at each stage after work-up with base. Reagents and conditions (isolation of intermediates at each stage): Forward transport (blue-to-green): a) $\mathrm{CF}_{3} \mathrm{CO}_{2} \mathrm{H}$ (3 equiv.), $\mathrm{C}_{2} \mathrm{D}_{2} \mathrm{Cl}_{4} / \mathrm{C}_{6} \mathrm{D}_{5} \mathrm{CD}_{3}\left(1: 2,2.5 \mathrm{mM}\right.$ ), then $\mathrm{I}_{2}$ (1.5 equiv.), r. t., 2 mins, $95 \%$; b) $\mathrm{CF}_{3} \mathrm{CO}_{2} \mathrm{H}$ (70 equiv.), $\mathrm{C}_{2} \mathrm{D}_{2} \mathrm{Cl}_{4} / \mathrm{C}_{6} \mathrm{D}_{5} \mathrm{CD}_{3}(1: 2,2.5 \mathrm{mM}$ ), r. t., $6 \mathrm{~h}$, then $\mathrm{Et}_{3} \mathrm{~N}$ (140 equiv.), $83 \%$; c) TCEP.HCl (5 equiv.), $\mathrm{Et}_{3} \mathrm{~N}$ (20 equiv.), $\mathrm{C}_{2} \mathrm{D}_{2} \mathrm{Cl}_{4} /\left(\mathrm{CD}_{3}\right)_{2} \mathrm{SO}$ (2:1, 2.5 $\mathrm{mM}, 1 \% \mathrm{v} / \mathrm{v} \mathrm{H}_{2} \mathrm{O}$ ), r. t., 1 h, $99 \%$. Backward transport (green-to-blue): d) $\mathrm{Et}_{3} \mathrm{~N}$ (3 equiv.), $\mathrm{C}_{2} \mathrm{D}_{2} \mathrm{Cl}_{4}(5$ $\mathrm{mM})$, r. t., then $\mathrm{I}_{2}$ (1.5 equiv.), 2 mins, $95 \%$; e) $\mathrm{CF}_{3} \mathrm{CO}_{2} \mathrm{H}$ (5 equiv.), $\mathrm{C}_{2} \mathrm{D}_{2} \mathrm{Cl}_{4}(5 \mathrm{mM})$, r. t., $6 \mathrm{~d}$, then $\mathrm{Et}_{3} \mathrm{~N}$ (10 equiv.), $91 \%$; f) TCEP.HCl (5 equiv.), $\mathrm{Et}_{3} \mathrm{~N}$ (20 equiv.), $\mathrm{C}_{2} \mathrm{D}_{2} \mathrm{Cl}_{4} /\left(\mathrm{CD}_{3}\right)_{2} \mathrm{SO}(2: 1,5 \mathrm{mM}, 1 \%$ v/v $\mathrm{H}_{2} \mathrm{O}$ ), r. t., 16 h, $99 \%$. Reagents and conditions (one-pot operation): Forward transport (blue-togreen): $E Z$-1-left in $\mathrm{C}_{2} \mathrm{D}_{2} \mathrm{Cl}_{4} / \mathrm{C}_{6} \mathrm{D}_{5} \mathrm{CD}_{3}(1: 2,2.5 \mathrm{mM})$ : a) $\mathrm{CF}_{3} \mathrm{CO}_{2} \mathrm{H}$ (3 equiv.), then $\mathrm{I}_{2}$ (1.5 equiv.), r. t., 2 mins; b) $\mathrm{CF}_{3} \mathrm{CO}_{2} \mathrm{H}$ (70 equiv.), r. t., $6 \mathrm{~h}$, then $\mathrm{Et}_{3} \mathrm{~N}$ (100 equiv.); c) TCEP.HCl (5 equiv., in $\left(\mathrm{CD}_{3}\right)_{2} \mathrm{SO}, 1 \% \mathrm{v} / \mathrm{v} \mathrm{H}_{2} \mathrm{O}$ ), r. t., 90 mins. EZ-1-right $72 \%$ (over three steps). Backward transport (green- 
to-blue): EZ-1-right in $\mathrm{C}_{2} \mathrm{D}_{2} \mathrm{Cl}_{4} / \mathrm{C}_{6} \mathrm{D}_{5} \mathrm{CD}_{3}(1: 2,2.5 \mathrm{mM})$ : d) $\mathrm{Et}_{3} \mathrm{~N}$ (3 equiv.), then $\mathrm{I}_{2}$ (1.5 equiv.), r. t., 2 mins; e) $\mathrm{CF}_{3} \mathrm{CO}_{2} \mathrm{H}$ (8 equiv.), r. t., $11 \mathrm{~d}$, then $\mathrm{Et}_{3} \mathrm{~N}$ (30 equiv.); f) TCEP.HCl (5 equiv., in $\left(\mathrm{CD}_{3}\right)_{2} \mathrm{SO}$, $1 \%$ v/v $\mathrm{H}_{2} \mathrm{O}$ ), r. t., 90 mins. EZ-1-left $63 \%$ (over three steps).

We first established conditions for using the molecular robotic arm to transport the 3mercaptopropanehydrazide cargo from the blue platform site to the green platform site (Fig. 4, steps a-c). The arm of EZ-1-left was attached to the cargo by kinetically-controlled disulfide bond formation. Addition of 3 equiv. $\mathrm{CF}_{3} \mathrm{CO}_{2} \mathrm{H}$ converted the EZ-1-left mixture to a single species within a few seconds $\left(Z-\mathbf{1}-\mathrm{H}^{+}\right.$-left, see Supplementary Fig. $\left.1 \mathrm{~b}\right)$, in which the arm is oriented towards the cargo on the blue platform station (Fig. 4, step a). This facilitated the rapid conversion to macrocycle Z-2-left, in $95 \%$ yield, upon subsequent addition of iodine. A solution of Z-2-left in $\mathrm{C}_{2} \mathrm{D}_{2} \mathrm{Cl}_{4} / \mathrm{C}_{6} \mathrm{D}_{5} \mathrm{CD}_{3}$ (1:2) was allowed to equilibrate at room temperature in the presence of 70 equivalents of $\mathrm{CF}_{3} \mathrm{CO}_{2} \mathrm{H}$ (Fig. 4, step b) and the process monitored by ${ }^{1} \mathrm{H}$ NMR (see Supplementary Fig. 3). Protonation of the hydrazone switch occurred rapidly, accompanied more slowly by acyl hydrazone exchange, and after $6 \mathrm{~h}$ a 17:83 mixture of Z-2$\mathrm{H}_{3}{ }^{3+}$-left:Z-2- $\mathrm{H}_{3}{ }^{3+}$-right was obtained. The mechanism of rotary switching and relocation of the cargo is shown in Fig. 5 (top pathway). ${ }^{26,30}$ Neutralizing with excess $\mathrm{Et}_{3} \mathrm{~N}$ gave a mixture of $Z$-2left and E-2-right where $83 \%$ of the cargo had been transported to the green site. Finally the cargo was released from the robotic arm and the switch reset by quantitative reduction of the disulfide bond in E-2-right with TCEP in $\mathrm{C}_{2} \mathrm{D}_{2} \mathrm{Cl}_{4} /\left(\mathrm{CD}_{3}\right)_{2} \mathrm{SO}$ (2:1) (Fig. 4, step c) to yield EZ-1right. The overall efficiency of the repositioning of the 3-mercaptopropanehydrazide from the blue platform site to the green platform site was $79 \%$ (Fig. 4, steps a-c).

Next, we turned our attention to backward transport, and a related set of reaction conditions (configuring the rotary switch in the opposite sense) allowed cargo translocation from the green to the blue platform site (Fig. 4, steps d-f). EZ-1-right was oxidized to macrocycle $E$-2right in $95 \%$ yield, using $\mathrm{Et}_{3} \mathrm{~N}$ (to neutralize hydrogen iodide formed during the reaction) and iodine in $\mathrm{C}_{2} \mathrm{D}_{2} \mathrm{Cl}_{4}$ (Fig. 4, step d). Five equivalents of $\mathrm{CF}_{3} \mathrm{CO}_{2} \mathrm{H}$ were added to a solution of macrocycle E-2-right in $\mathrm{C}_{2} \mathrm{D}_{2} \mathrm{Cl}_{4}$ (Fig. 4, step e) and the reaction monitored by ${ }^{1} \mathrm{H}$ NMR (see Supplementary Fig. 9). Protonation of E-2-right rapidly generated a mixture of $E-\mathbf{2}-\mathrm{H}_{2}{ }^{2+}$-right and $\mathrm{Z}-2-\mathrm{H}_{2}{ }^{2+}$-right, which converted slowly to $>90 \% \mathrm{Z}-2-\mathrm{H}_{2}{ }^{2+}$-left over a period of six days (Fig. 5, bottom pathway). Hydrazone exchange is an acid-catalysed process, so the longer reaction time is consistent with the amount of $\mathrm{CF}_{3} \mathrm{CO}_{2} \mathrm{H}$ present. After neutralization with $\mathrm{Et}_{3} \mathrm{~N}$ a ratio of 91:9 Z-2-left:E-2-right was obtained. Reduction of the disulfide bond with TCEP (Fig. 4, step 
f) released the cargo from the robotic arm, affording EZ-1-left with an overall efficiency of $85 \%$ for the three step operation (Fig. 4, d-f).

Molecular machine $\mathbf{1}$ utilizes an energy ratchet mechanism ${ }^{24,31-33}$ to directionally transport the cargo. The rotary switch state determines the thermodynamic stability of cargo bound to both arm and platform; the switchable lability of the cargo-arm and cargo-platform interactions changes the relative heights of kinetic barriers leading to transport in the chosen direction. Pleasingly, during all of these steps the machine was found to operate with high positional integrity and no over-reaching of the cargo was detected (placing of the cargo at the 'wrong' site from a particular arm position). Nor was any 'machine-minus-cargo' nor 'machine-plusadditional-cargo' detected by mass spectrometry at any stage of the transporter operation (see Supplementary Figs 2, 4, 6, 8, 10 and 12) indicating that the re-positioning of the cargo between the blue and green platform sites occurs overwhelmingly via the robotic arm mechanism (i.e. intra-machina) and there is no exchange (within the limits of detection of the experiment, $\sim 1 \%$ ) with other machines nor with other molecules in the bulk.

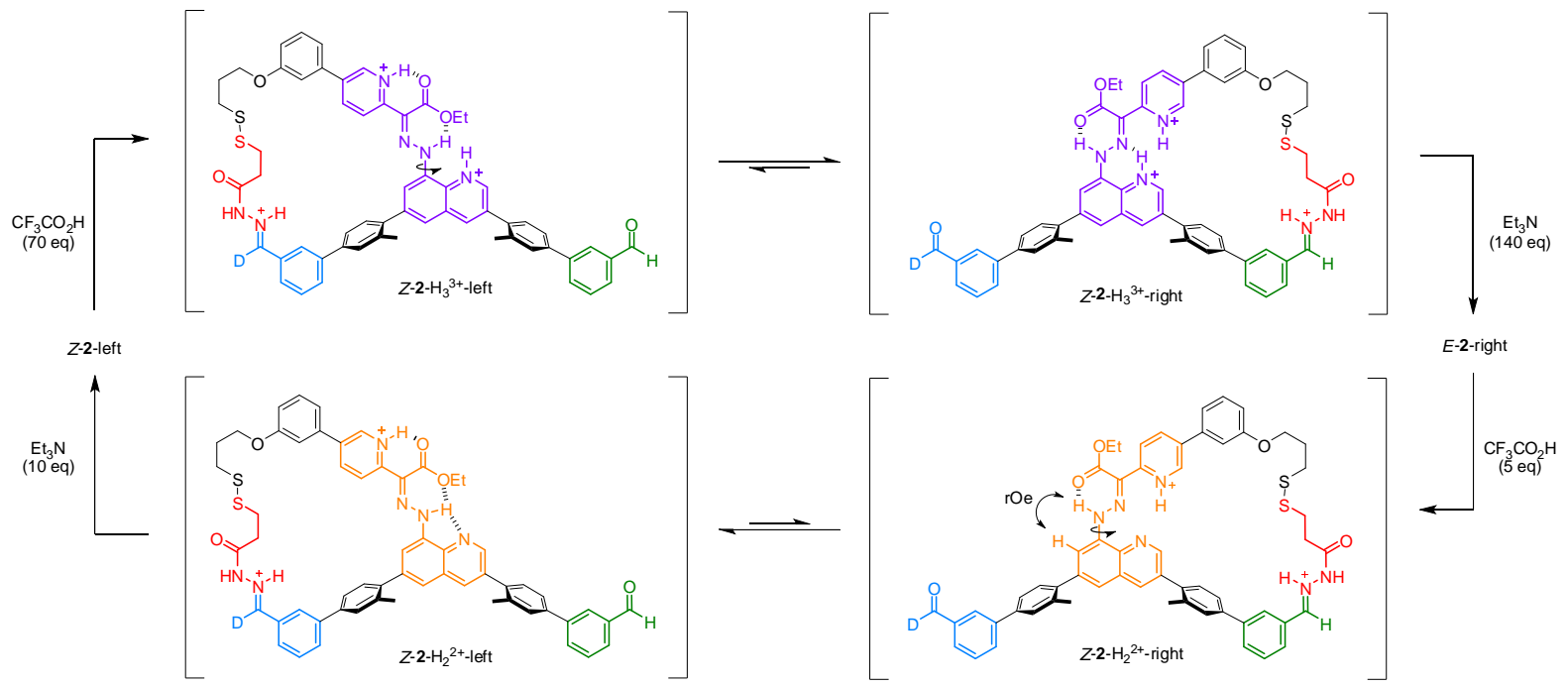

Figure 5. Presumed intermediates in the rotary switching ${ }^{26}$ and cargo transport mechanism. Forward transport (top pathway, blue-to-green): protonation of Z-2-left with 70 equivalent of $\mathrm{CF}_{3} \mathrm{CO}_{2} \mathrm{H}$ affords $\mathrm{Z}-2-\mathrm{H}_{3}{ }^{3+}$-left which undergoes rotation about the $\mathrm{C}-\mathrm{N}$ rotor-stator single bond to give $\mathrm{Z}-2-\mathrm{H}_{3}{ }^{3+}$-right (the platform-substrate hydrazone $\mathrm{C}=\mathrm{N}$ bond is dynamic under these conditions). Deprotonation of $\mathrm{Z}-\mathbf{2}-\mathrm{H}_{3}{ }^{3+}$-right generates an intermediate that subsequently relaxes through imine bond isomerisation and $\mathrm{C}-\mathrm{N}$ bond rotation into the more stable E-2-right form. Backward transport (bottom pathway, green-to-blue): protonation of $E$-2-right with 5 equivalents of $\mathrm{CF}_{3} \mathrm{CO}_{2} \mathrm{H}$ gives Z-2$\mathrm{H}_{2}{ }^{2+}$-right which undergoes rotation about the C-N rotor-stator single bond to generate $Z-2-\mathrm{H}_{2}{ }^{2+}$-left (the platform-substrate hydrazone $\mathrm{C}=\mathrm{N}$ bond is dynamic under these conditions), affording Z-2-left after neutralisation. See Supplementary Figs 3 and 9 for ${ }^{1} \mathrm{H}$ NMR spectra of these processes.

\section{One-pot transport}


Having developed general conditions for forward and backward transport, we demonstrated that the robotic machine operation can be performed in one-pot, without isolating the intermediates after each operation, i.e. in response to a programmed sequence of chemical inputs. Forward transport was performed on EZ-1-left in $\mathrm{C}_{2} \mathrm{D}_{2} \mathrm{Cl}_{4} / \mathrm{C}_{6} \mathrm{D}_{5} \mathrm{CD}_{3}$ (1:2) through the sequential addition of the three sets of reagents (a, b and c) shown in Fig. 4, resulting in a $72 \%$ yield of EZ-1-right (90 \% per step). Backward operation was performed on EZ-1-right also in $\mathrm{C}_{2} \mathrm{D}_{2} \mathrm{Cl}_{4} / \mathrm{C}_{6} \mathrm{D}_{5} \mathrm{CD}_{3}$ (1:2) according to the conditions $\mathrm{d}$, e and $\mathrm{f}$ (Fig. 4 ) giving a $63 \%$ yield of EZ1-left (86\% per step).

\section{Conclusions}

We have synthesized and operated a novel molecular device capable of selectively transporting a small-molecule cargo in either direction between two sites $2 \mathrm{~nm}$ apart on a molecular platform. An efficient three-stage operation utilizes a pH-responsive rotary switch to steer a molecular robotic arm that can grip or release a cargo through disulfide bond formation, together with a dynamic hydrazone linkage used to bind the cargo to the platform sites. We envisage that such systems will be useful for the development of molecular-sized machines that can manipulate substrates to control molecular construction, ${ }^{34}$ in a manner reminiscent of that observed in fatty acid synthase and factory assembly lines.

\section{Supplementary Information}

Detailed synthetic procedures, operation methods and full characterization data.

\section{Author Contributions}

AM and DAL planned the project. SK, ATLL, AM and JS carried out the experimental work. DAL directed the research. All the authors contributed to the analysis of the results and the writing of the manuscript.

\section{Corresponding Author}

david.leigh@manchester.ac.uk.

\section{Notes}

The authors declare no competing financial interest. 


\section{Acknowledgements}

We thank the Engineering and Physical Sciences Research Council (EPSRC) for funding and the EPSRC National Mass Spectrometry Service Centre (Swansea, UK) for high resolution mass spectrometry.

Word Count (not including references) 3675.

\section{References}

1. Feynman, R. P. There's plenty of room at the bottom. Eng. Sci. 23, 22-36 (1960).

2. Drexler, K. E. Molecular engineering: An approach to the development of general capabilities for molecular manipulation. Proc. Natl Acad. Sci. USA 78, 5275-5278 (1981).

3. Drexler, K. E. Nanosystems: Molecular Machinery, Manufacturing, and Computation. (John Wiley \& Sons, New York, 1992).

4. Kumagai, T., et al. Controlling intramolecular hydrogen transfer in a porphycene molecule with single atoms or molecules located nearby. Nature Chem. 6, 41-46 (2014).

5. Smalley, R. E. Of chemistry, love and nanobots. Sci. Am. 285, 76-77 (2001).

6. Whitesides, G. M. The once and future nanomachine. Sci. Am. 285, 78-83 (2001).

7. Jones, R. A. L. Soft Machines: nanotechnology and life. (Oxford University Press, Oxford, 2004).

8. Maier, T., Leibundgut, M. \& Ban, N. The crystal structure of a mammalian fatty acid synthase. Science 321, 1315-1322 (2008).

9. Brignole, E. J., Smith, S. \& Asturias, F. J. Conformational flexibility of metazoan fatty acid synthase enables catalysis. Nature Struct. Mol. Biol. 16, 190-197 (2009).

10. Chan, D. I. \& Vogel, H. J. Current understanding of fatty acid biosynthesis and the acyl carrier protein. Biochem. J. 430, 1-19 (2010).

11. Ding, B. \& Seeman, N. C. Operation of a DNA robot arm inserted into a 2D DNA crystalline substrate. Science 314, 1583-1585 (2006).

12. Gu, H., Chao, J., Xiao, S.-J. \& Seeman, N. C. A proximity-based programmable DNA nanoscale assembly line. Nature 465, 202-205 (2010).

13. von Delius, M. \& Leigh, D. A. Walking molecules. Chem. Soc. Rev. 4o, 3656-3676 (2011).

14. Berná, J., et al. Macroscopic transport by synthetic molecular machines. Nature Mater. 4, 704-710 (2005). 
15. Liu, Y., et al. Linear artificial molecular muscles. J. Am. Chem. Soc. 127, 9745-9759 (2005).

16. Eelkema, R., et al. Molecular machines: Nanomotor rotates microscale objects. Nature 440, 163 (2006).

17. Li, Q., et al. Macroscopic contraction of a gel induced by the integrated motion of lightdriven molecular motors. Nature Nanotech. 10, 161-165 (2015).

18. Kay, E. R \& Leigh, D. A. Rise of the molecular machines. Angew. Chem. Int. Ed. 54, 1008010088 (2015).

19. Muraoka, T., Kinbara, K. \& Aida, T. Mechanical twisting of a guest by a photoresponsive host. Nature 440, 512-515 (2006).

20. Erbas-Cakmak, S., Leigh, D. A., McTernan, C. T. \& Nussbaumer, A. L. Artificial molecular machines. Chem. Rev. 115, 10081-10206 (2015).

21. Astumian, R. D. Design principles for Brownian molecular machines: how to swim in molasses and walk in a hurricane. Phys. Chem. Chem. Phys. 9, 5067-5083 (2007).

22. von Delius, M., Geertsema, E. M. \& Leigh, D. A. A synthetic small molecule that can walk down a track. Nature Chem. 2, 96-101 (2010).

23. von Delius, M., Geertsema, E. M., Leigh, D. A. \& Tang, D.-T. D. Design, synthesis, and operation of small molecules that walk along tracks. J. Am. Chem. Soc. 132, 16134-16145 (2010).

24. Barrell, M. J., Campaña, A. G., von Delius, M., Geertsema, E. M. \& Leigh, D. A. Light-driven transport of a molecular walker in either direction along a molecular track. Angew. Chem. Int. Ed. 50, 285-290 (2011).

25. Feringa, B. L. \& Browne, W. R. (eds) Molecular Switches, Second Edition (Wiley-VCH, Weinheim, Germany, 2011).

26. Su, X. \& Aprahamian, I. Switching around two axles: Controlling the configuration and conformation of a hydrazone-based switch. Org. Lett. 13, 30-33 (2011).

27. Su, X., Robbins, T. F. \& Aprahamian, I. Switching through coordination-coupled proton transfer. Angew. Chem. Int. Ed. 50, 1841-1844 (2011).

28. Ray, D., Foy, J. T., Hughes, R. P. \& Aprahamian, I. A switching cascade of hydrazone-based rotary switches through coordination-coupled proton relays. Nature Chem. 4, 757-762 (2012).

29. Japp, F. R. \& Klingemann, F. Ueber benzolazo- und benzolhydrazofettsäuren. Ber. Dtsch. Chem. Ges. 20, 2942-2944 (1887).

30. Landge, S. L., et al. Isomerization mechanism in hydrazone-based rotary switches: lateral shift, rotation, or tautomerization? J. Am. Chem. Soc. 133, 9812-9823 (2011).

31. Astumian, R. D. \& Derényi, I. Fluctuation driven transport and models of molecular motors and pumps. Eur. Biophys. J. 27, 474-489 (1998). 
32. Hernández, J. V., Kay, E. R. \& Leigh, D. A. A reversible synthetic rotary molecular motor. Science 306, 1532-1537 (2004).

33. Ragazzon, G., Baroncini, M., Silvi, S., Venturi, M. \& Credi, A. Light-powered autonomous and directional molecular motion of a dissipative self-assembling system. Nature Nanotech. 10, 70-75 (2015).

34. Lewandowski, B., et al. Sequence-specific peptide synthesis by an artificial small-molecule machine. Science 339, 189-193 (2013).

\section{Graphical Abstract}

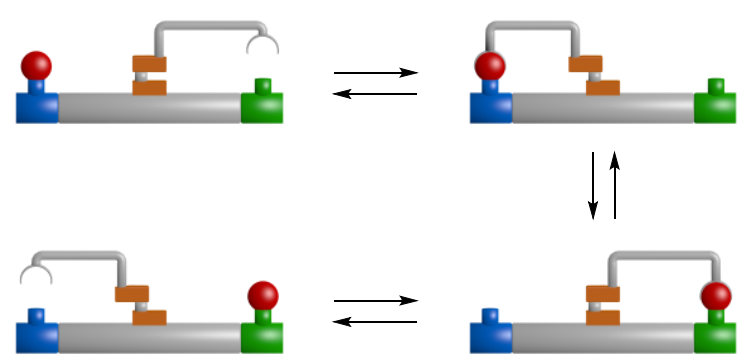

